\title{
THE ROLE OF HERBAL EXTRACTS IN KNEE OSTEOARTHRITIS FEMALES REHABILITATION
}

\author{
RODICA TRĂISTARU ${ }^{1 \#}$, DRAGOȘ OVIDIU ALEXANDRU ${ }^{2 \# *}$, DIANA KAMAL ${ }^{3 \#}$, KAMAL $^{2 \sharp}$ \\ CONSTANTIN KAMAL ${ }^{4 \#}$, OTILIA ROGOVEANU ${ }^{1 \#}$ \\ ${ }^{I}$ University of Medicine and Pharmacy of Craiova, Physical and Rehabilitation Medicine Department, 2-4 Petru Rareș Street, \\ 200349, Craiova, Romania \\ ${ }^{2}$ University of Medicine and Pharmacy of Craiova, Department of Medical Informatics and Biostatistics, 2-4 Petru Rareș \\ Street, 200349, Craiova, Romania \\ ${ }^{3}$ Medical Clinic Elga, Craiova, 2 Mihai Eminescu Street, 200131, Craiova, Romania \\ ${ }^{4}$ University of Medicine and Pharmacy of Craiova, Family Medicine Department, 2-4 Petru Rareș Street, 200349, Craiova, Romania \\ *corresponding author: dragosado@yahoo.com \\ \# All authors have equal contribution
}

Manuscript received: August 2017

\begin{abstract}
In our observational study, we intend to set off the importance of an herbal complex based on Boswellia serrata in the rehabilitation of the complete status of females with knee osteoarthritis. An association between herbal extracts and rehabilitation methods will give the ideal healthcare for these patients.
\end{abstract}

\section{Rezumat}

Studiul observațional a urmărit rolul asocierii unui preparat din plante, bazat pe Boswellia serrata, în programul de reabilitare și controlul statusului clinic-funcțional al femeilor cu gonartroză primară. Asocierea judicioasă dintre produsele naturale și metodele de reabilitare (kinetoterapie) conferă soluția ideală pentru o calitate optimă a vieții pacientelor.

Keywords: knee osteoarthritis, herbal product, rehabilitation program

\section{Introduction}

Osteoarthritis (OA), a painful chronic disorder involving all components of synovial joint, represents one of the most frequent causes of physical disability [13]; according to the World Health Organization, OA is on the top ten disabling chronic disorders in developed states $[15,23,31]$. The joint most ordinarily interested by OA is the knee (knee OA - KOA - constitutes $83 \%$ of the global disease burden for OA) - the middle pivot of the lower limb with biomechanical role in walking and orthostatic posture [17]. Older age and female gender are two of the risk factors significantly associated with the onset of KOA, in accordance with the literature data [28]. Serious pain, a trademark symptom of KOA, affects activities of daily living [32] and is a leading risk factor for enhanced fall risk with major dysfunctional impact on the body [33].

OA has a multifactorial aetiology [35] and its pathogenesis involve mechano-transduction, the interaction between protease inhibitors, metalloproteases (MMP13, MMP3) and cytokines on cartilage change and mechanisms of its sole. Cytokines including tumour necrosis factor $\alpha(\mathrm{TNF} \alpha)$ and interleukin-1 (IL-1) - probably the foremost cytokines for cartilage deterioration, other cytokines (members of the IL-6 protein super family, IL-7, IL-17, IL-18) can elevate joint cartilage extracellular matrix protein abasement or action with other cytokines, to intensify and speed this process $[2,19]$. In the last decade, former cytokines were also known as being implicated in the progressive degradation of joint cartilage tissue. Catabolic metalloproteinases (MMP) are activated by the factor hypoxiainducible factor- $2 \alpha$ (HIF-2 $\alpha$ ) transcription, a complex process which is involved significantly in chondrocyte apoptosis and OA cartilage. Anabolic cytokines, including insulin-like growth factor-1 (IGF-1), fibroblast growth factor-2 (FGF-2), and transforming growth factor-beta (TGF- $\beta$ ), have been qualified as possible chondroprotective factors [19]. Monocytes promote the synovitis process and disorder pathogenesis. These cells generate high levels of IL-1 $\beta$ and TNF compared to healthy persons [18].

Medical care in osteoarthritis is provided by a multidisciplinary team and may be challenging because of the co-morbidities that coincide with OA [11]. In the last years, it was mentioned in the medical literature the major role of herbal care for OA patients. This type of treatment is in accordance with actual mentioned challenges in treating OA (limited potency of present 
therapies, contraindications to management because of other disorders, lack of access or availability to treatments, difficulties with patients adhering to treatments) [11]. A phytotherapeutical Indian complex is administered to OA patient in two forms - topical and tablet, since forty years ago [30]. These tablets and creams are reported to be beneficial on the whole complex of complaints associated with OA disorders and are completely non-toxic. They are slow acting and need long-term therapy [5]. The combination of several herbs in the tablet is changing in time. Today, the formulation contains six herbal extracts as active ingredients: Alpinia galanga $70 \mathrm{mg}$, Boswellia serrata $240 \mathrm{mg}$, Commiphora wightii $200 \mathrm{mg}$, Glycyrrhiza glabra $70 \mathrm{mg}$, Tinospora cordifolia $60 \mathrm{mg}$ and Tribulus terrestris $60 \mathrm{mg}$ [7]. The phytocomplex contains: saponin triterpenes, flavonoids and other components such as amino acids, coumarins, tannins, sugars, starch, phyto-sterols and choline. This herbal complex improves the patient's condition through an antiinflammatory activity, by suppressing the cyclooxygenase activity and prostaglandin formation, retarding the platelet aggregation, enhancing the antioxidant activity and scavenging the free radicals, inhibiting the expression of pro-inflammatory cytokines. It modulates the metabolic profile by promoting insulin secretion, by inhibiting gluconeogenesis and glycogenolysis, lowering the cholesterol-induced hyperlipidaemia and decreasing the hepatic steroid production. It stimulates the growth of bone forming cells, modifies the protein inside the bacterial cell wall, decreases the activity of tyrosinase, and the serum transaminase levels. It also possesses acetylcholinesterase inhibitory effects, enhances the levels of cerebral dopamine and the specific immune responses [11, 34, 37-39].

In our observational study, we intend to set off the importance of the phytocomplex based on Boswellia serrata, tablets and topical formulation, in the rehabilitation of the complex status of female patients with KOA. The association between herbal products and rehabilitation methods will give the optimal healthcare for KOA patients.

\section{Materials and Methods}

Study design. The research was performed on 57 females; all diagnosed with KOA, during the period May 2017 - November 2017 in the Rehabilitation Department of the "Filantropia" Hospital Craiova, Romania. Our study was authorized by the ethics review hospital board and a signed informed consent from all the subjects was registered. We completed initial etiopathogenic, clinical (flexion angle of the knee), laboratory (laboratory tests, knee X-ray and knee ultrasound) and functional evaluations using the VAS - Visual Analogue Scale for pain, the WOMAC scale to assess the impact in performing activities of daily living, the Lequesne Index to assess the effectiveness of therapeutic interventions. Assessment of our patients was performed in three periods - first (T1), after 3 months (T2) - during which an in-hospital rehabilitation was carried on, and after a further 3 months (T3) in an outpatient evaluation. The rehabilitation objectives were: knee aching control; managing the inflammatory process; recovering motor control, optimal knee function and maintain the quality life of patients. The rehabilitation program was complex, based on non-surgical measures and comprised: non-pharmacological aspects educational, dietary and hygienic, posture, physical (electrotherapy - TENS, ultra-sound, magnetodiaflux, and thermotherapy - paraffin), massage and kinetic exercises; pharmacological measures - herbal complex based on Boswellia serrata, 2 tablets per day, were given for 3 months.

Statistical analysis was carried out using the following: Microsoft Excel (Microsoft Corp., Redmond, WA, USA), XLSTAT add-on for MS Excel (Addinsoft SARL, Paris, France) and IBM SPSS Statistics 20.0 (IBM Corporation, Armonk, NY, USA) for refining the data. We used $\mathrm{Z}$ test for quotients, to analyse the statistical significance of the difference between the frequency $f$ of binary variables in general population and the determined frequency $\mathrm{p}$ in our representative group.

Because the study involved numerical comparisons between 3 sets of data from the same patients, recorded during 3 different visits, that did not have normal (Gaussian) distributions, we used the median, quartiles and minimum-maximum to describe the numerical data, and the nonparametric Friedman test, followed by post-hoc comparisons to see significant differences between patients.

\section{Results and Discussion}

Our study group consisted in 57 women, aged 41 to 82 (Table I) and the differences concerning the area of residence were not significant $(Z$ test $p=0.836$ ) with $54 \%$ urban, $46 \%$ rural. The age distribution shows a slight asymmetry towards older ages. The weight analysis showed a great asymmetry towards a higher body mass index (BMI), only $8.57 \%$ of patients being normoponderal. 
Table I

Characteristics of the studied patients

\begin{tabular}{|l|c|c|c|c|c|c|}
\hline \multicolumn{9}{|c|}{ Biographic data } & Total \\
\hline Residence & \multicolumn{3}{|c|}{30 patients Urban $=52.63 \%$} & \multicolumn{2}{|c|}{27 patients Rural $=47.37 \%$} & 57 patients \\
\hline \multirow{2}{*}{ Age } & $40-49$ years & $50-59$ years & $60-69$ years & $70-79$ years & $80-89$ years & \multirow{2}{*}{$100 \%$} \\
\cline { 2 - 6 } & $5.26 \%$ & $21.05 \%$ & $42.11 \%$ & $26.32 \%$ & $5.26 \%$ & \\
\hline \multirow{2}{*}{ Weight } & Normal & Overweight & Obese I & Obese II & Obese III & \multirow{2}{*}{$100 \%$} \\
\cline { 2 - 6 } & $7.02 \%$ & $40.35 \%$ & $31.58 \%$ & $17.54 \%$ & $3.51 \%$ & \\
\hline
\end{tabular}

Comparing the values recorded for the flexion angle among the three visits (Table II), we observed a steady increase in the values, the overall differences being highly significant (Friedman, $p<0.001$ ) (Figure 1). Performing post-hoc analysis, we found the values from the second visit to be greater than the initial values, and the values from the last visit being significantly higher than the intermediate values. Analysing the visual-analogue scale recordings, we found highly significant differences among the three

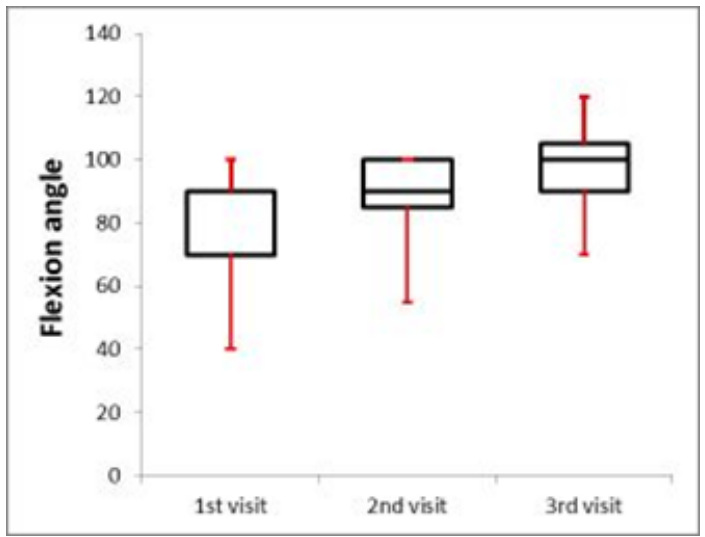

Figure 1.

Comparison of flexion angle values among the three visits

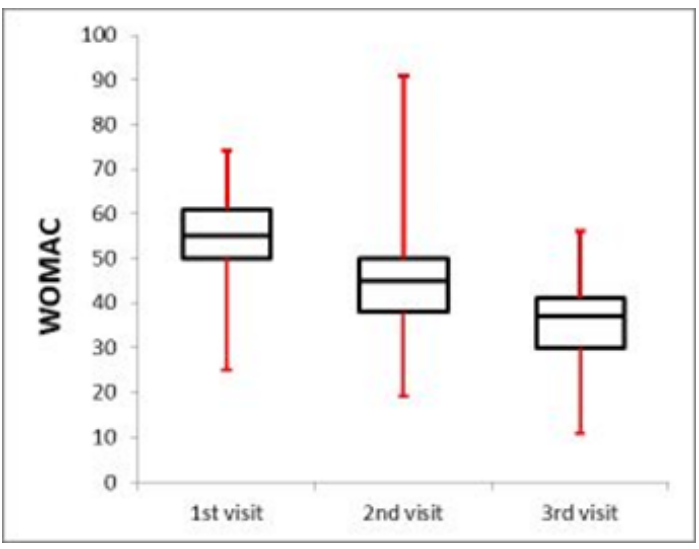

Figure 3.

Comparison of WOMAC values among the three visits visits, the values decreasing over time (Friedman $\mathrm{p}<0.001)$; the post-hoc analysis showed the values from the first visit being lower than the values form the second visit, which were significantly lower than the values from the third visit (Figure 2). The finding for the WOMAC scale values (Figure 3) and the Lequesne functional index values (Figure 4) were similar to those for VAS, showing a highly significant decrease over time (Friedman, $\mathrm{p}<0.001$ ) (Table II).

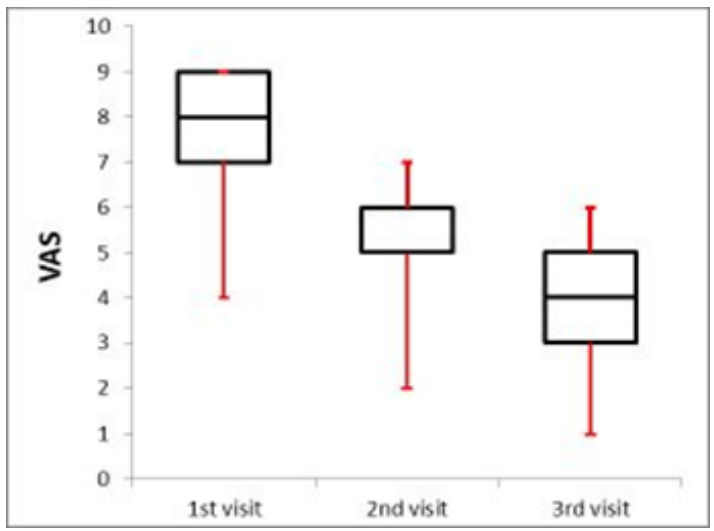

Figure 2.

Comparison of VAS values among the three visits

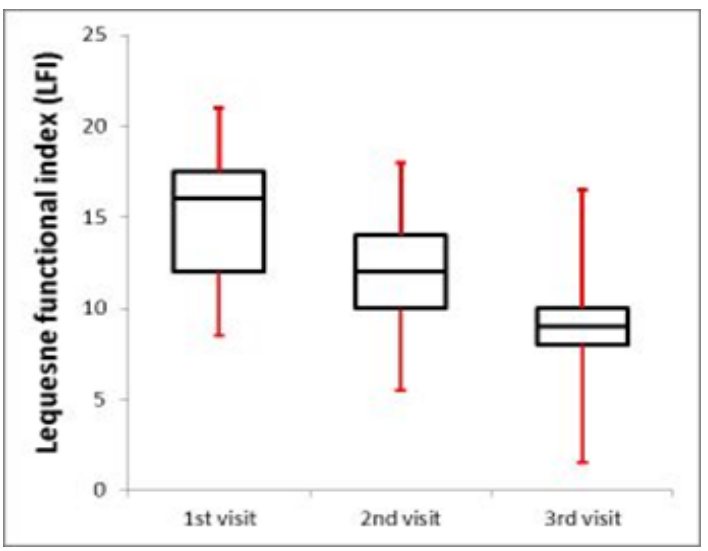

Figure 4.

Comparison of Lequesne functional index values among the three visits 
Table II

Median and spread indicators for the study variables

\begin{tabular}{|c|c|c|c|c|c|c|}
\hline \multirow{2}{*}{$\begin{array}{c}\text { Variable } \\
\text { Parameter }\end{array}$} & \multicolumn{3}{|c|}{ Flexion angle } & \multicolumn{3}{|c|}{ VAS } \\
\hline & T1 & T2 & T3 & T1 & T2 & T3 \\
\hline Minimum & 40 & 55 & 70 & 4 & 2 & 1 \\
\hline 1st Quartile & 70 & 85 & 90 & 7 & 5 & 3 \\
\hline Median & 90 & 90 & 100 & 8 & 6 & 4 \\
\hline 3rd Quartile & 90 & 100 & 105 & 9 & 6 & 5 \\
\hline Maximum & 100 & 100 & 120 & 9 & 7 & 6 \\
\hline Variable & \multicolumn{3}{|c|}{ WOMAC } & \multicolumn{3}{|c|}{ Lequesne functional index } \\
\hline Parameter & T1 & $\mathrm{T2}$ & T3 & T1 & T2 & T3 \\
\hline Minimum & 25 & 19 & 11 & 8.5 & 5.5 & 1.5 \\
\hline 1st Quartile & 50 & 38 & 30 & 12 & 10 & 8 \\
\hline Median & 55 & 45 & 37 & 16 & 12 & 9 \\
\hline 3rd Quartile & 61 & 50 & 41 & 17.5 & 14 & 10 \\
\hline Maximum & 74 & 91 & 56 & 21 & 18 & 16.5 \\
\hline
\end{tabular}

Analysing the correlation between the increase in the flexion angle and the decrease of the perceived pain or discomfort in performing day to day functions, using Spearman's rho correlation coefficient, we found

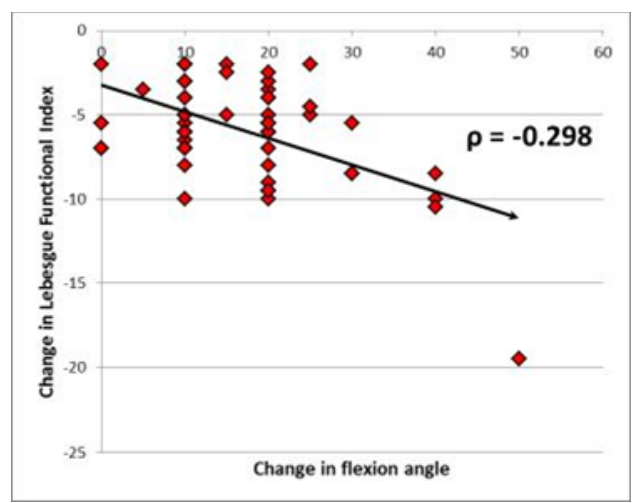

Figure 5.

Correlation between flexion angle changes and LFI changes during the study the Lequesne functional index to show the greatest correlation to the flexion angle $(\rho=-0.298)$ (Figure 5), followed by WOMAC scale $(\rho=-0.278)$ (Figure 6) and VAS $(\rho=-0.210)$ (Figure 7) (Table II).

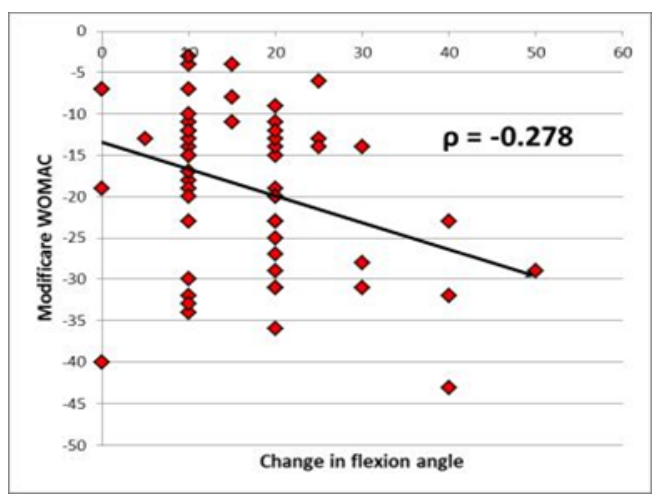

Figure 6.

Correlation between flexion angle changes and WOMAC changes during the study

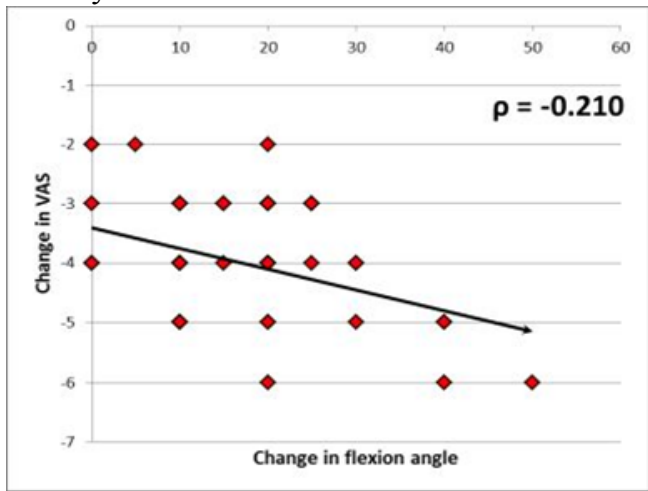

Figure 7.

Correlation between flexion angle changes and VAS changes during the study

Our study is the first clinical analysis in Romania to assess the efficacy of this complex herbal based on Boswellia serrata in KOA females. Our study confirms the significant repair of symptoms like aching, joint protrude, articular dysfunction and mobility in patients with OA due to these herbal extracts. None of the females reported any significant adverse effects during the six studied months. There was no adjustment in the lab parameters in the studied patients. Our observational study was performed taking into consideration an association between herbal treatment and rehabilitation program. The weakness of our study is the lack of a control placebo group, a difficult aspect in the rehabilitation medicine. 
Going over the similar studies, it shows the various clinical benefits of derivates based on Boswellia serrata treatment in KOA patients, without age limits and supervised rehabilitation program [5]. The herbal tablets appear to be adequate and secure supplements for management of OA-patients [16], as it is proved in a double blind, placebo-controlled study conducted to test the efficacy of phytocomplex in terms of alleviating pain, inflammation and enhancing joint mobility and safety [7]. There were not reported negative effects by any of the patients [27]. The clinical efficacy and analgesic effect of the herbals was comparable to that of the commonly used drugs, diclofenac sodium and ibuprofen [26, 29].

For the last two decades, formulations of herbal complex tablet containing extracts of Alpinia galanga, Commiphora wightii, Tinospora cordifolia, Glycyrrhiza glabra, Tribulus terrestris, and especially Boswellia serrata, proved to have anti-arthritic, anti-inflammatory, muscle relaxant, immunomodulatory and analgesic roles [11].

The product used in our study is polyherbal, containing extracts of Boswellia serrata, Commiphora wightii, Alpinia galanga, Glycyrrhiza glabra, Tribulus terrestris and Tinospora cordifolia.

Boswellia serrata is the primary and the most important component, which has been historically used in the treatment of OA. Boswellia serrata gum resin extract (BSE) containing boswellic acids (BAs) is the main bioactive principle. These BAs extracts have demonstrated their anti-inflammatory and anti-arthritic roles, with good management of musculo-skeletal pain and inflammation, due to various mechanisms of action like avoidance of decreased glycosaminoglycan synthesis, inhibition of inflammatory mediators and recovered blood supply to joint structures $[1,6]$. In vitro studies revealed that the boswellic acids, a group of pentacyclic triterpenoid compounds, and their acetylated derivatives inhibit the biosynthesis of leukotrienes, the proinflammatory 5-lipoxygenase products which cause increased permeability [8, 34]. In addition, 3acetyl-11-ketobeta-boswellic acid (AKBA) is a natural inhibitor of the transcription factor NFkB, whose attendance is a requirement for the formation/action of chemokines/cytokines involved in inflammatory reactions. This natural product also simultaneously reduces oxidative stress [36]. According to a Cochrane systematic review, BSE presents some benefits in the management of osteoarthritis, coupled with low side consequences, in clinical, placebo-controlled studies [11].

Alpinia galanga (galangal) is a common plant in the Southeast Asia. Phenolic compounds such as phenolic acids and flavonoids are the major constituents of this plant. The extracts of Alpinia galanga showed a complex role in the biochemical human status: platelet-activating factor (PAF)-inhibitory, acetyl- cholinesterase-inhibitory, antibacterial, antimicrobial, antifungal, antioxidant and apoptosis activities [26, 27]. Commiphora wightii (C. mukul) is a well-known medicinal plant since 3000 years ago, having wellknown biological properties [10, 27]. C. wightii contains a bitter gum known as Guggul (Myrrh) in stems and leaves. The pharmacological activities associated with Guggul gum include antibacterial, anti-inflammatory, antirheumatic, COX inhibitory, anticoagulant and hypolipidaemic actions that are mostly due to the existence of steroids compounds [20,38].

Glycyrrhiza glabra (licorice) has been regarded as an herbal product since ancient periods. Nowadays, it is a well-recognized spice that has good pharmacological effects [22]. Licochalcone A (Lico A), a flavonoid compound detected in the licorice root, has been mentioned to activate $\mathrm{Nrf} 2$ signalling pathway and to have anti-inflammatory activity in IL- $1 \beta$-stimulated chondrocytes [14]. Phytochemicals are well accepted as sources of pharmacologically efficacious therapy in the management of some oxidative stress related diseases. Methanol fraction of Glycyrrhiza glabra demonstrated optimal scavenging activity against nitric oxide free radicals and DPPH, proportionally to standard antioxidants [12].

Tinospora cordifolia (herb guduchi) has been used for long for its Rasayana properties to increase the vigour and immunity [4]. It is found to be safe on haematological and biochemical organ function tests and has muscle strengthening and lipid lowering action in healthy individuals [9]. Tinospora cordifolia can be taken daily as a prophylactic agent to prevent the long-term biochemical changes in the body and related adverse consequences on the heart and other body systems due to chronic activation of the sympathetic nervous system [4]. Guduchi treatment acts on the macrophages, enhances the tumouricidal activity against L929 fibroblast cells and increases the production of nitric oxide. Two types of kinases - tyrosine-specific protein kinase and protein kinase $\mathrm{C}$ - have an important role in the tumoricidal function mediated by guduchi [21].

Tribulus terrestris. Many different components with a variety of chemical structures and biological activities have been isolated from Tribulus terrestris, including amino acids, amide derivatives, glycosides, flavonoids, phytosterols, proteins, steroidal saponins, tannins, and terpenoids. From all different types of compounds, flavonoids (derivatives of isorhamnetin, kaempferol and quercetin) and steroidal saponins (protogracillin and protodioscin) are described to be the most important metabolites with various bioactivities and unique biological activities and complex pharmacological activities for cardiac protection and providing anti-inflammatory, antidiabetic, antioxidants, antitumour and anti-urolithic outcomes, also improving the sexual function [37, 39]. Previous studies have indicated that the ethanolic extract of 
FARMACIA, 2018, Vol. 66, 3

$T$. terrestris (EETT) is efficient in controlling inflammation by regulating IL-6, IL-10, COX-2, tumour necrosis factor- $\alpha$, and nitric oxide (NO) [24].

When herbal or medicinal plants are administered, we have to take into consideration the WHO guidelines for the definition of medicinal plant products [11]. All these medicinal plants may contain proinflammatory mediators and interact with various cytokines, at least under experimental studies. The mechanism of action of the oral herbal products seems to be similar to that of the non-steroidal antiinflammatory drugs. Although their mechanisms of action have not yet been established, completely interactions with cartilage destruction and mediators of inflammation give an argument for using them as supplements in patients with OA. The active principle of a medicinal plant product is the sum of all ingredients that produce the medicinal action, namely the phytocomplex. Despite their advantages, herbals elevate some concerns, such as their bioavailability, the lack of standardization, the drug - herbal interactions, the insufficient regulatory guidelines at national and international levels $[3,25]$.

\section{Conclusions}

The complex herbal product, based on Boswellia serrata, used in the present study, helps alleviate the pain and disability caused by KOA, promoting normal strength and flexibility of muscle and connective tissue, with enhancing the quality of life.

Physical therapy and kinetic programs in association with herbals represent the best therapy for females with KOA, which obviously contributes to the control of a progressive and irrevocable out-growth of arthritis disease.

In the following years, the controlled studies may be guided to consider the complex role of the herbal product for the complete management of KOA patients, including other localisations of the disease (hand, hip), in accordance with international recommendations for the medical management of osteoarthritis.

\section{References}

1. Abdel-Tawab M, Werz O, Schubert-Zsilavecz M, Boswellia serrata: an overall assessment of in vitro, preclinical, pharmacokinetic and clinical data. Clin Pharmacokinet., 2011; 50: 349-369.

2. Bârcă $M$, Manda $G$, Ciobanu $A M$, Bălălău $C$, Lupuleasa D, Burcea Dragomiroiu GTA, Anca Pop, Popa DE, Baconi DL, Immunomodulatory effects of methadone following methotrexate therapy in a rat model of arthritis. Farmacia, 2017; 65(3): 423-428.

3. Bharat AS, Tripathi RK, Petare AU, Raut AA, Rege NN, Effect of Tinospora cordifolia on physical and cardiovascular performance induced by physical stress in healthy human volunteers. Ayu, 2015; 36(3): 265-270.
4. Bhattaram VA, Graefe U, Kohlert C, Veit M, Derendorf $\mathrm{H}$, Pharmacokinetics and bioavailability of herbal medicinal products. Phytomedicine, 2002; 9(Suppl.): 1-33.

5. Biswajit S, Banerjee SK, De Mazumder N, Sarkar N, Alok R, Prabir M, Studies on effects of Rumalaya in osteoarthritis. Ind Med J., 1980; 11 (74): 151-154.

6. Cameron M, Chrubasik S, Oral herbal therapies for treating osteoarthritis. Cochrane Database Syst Rev., 2014; 5: 2947-3022.

7. Chandanwale AS, Kulkarni KS, Clinical evaluation of Rumalaya forte in osteoarthrosis. Medicine Update, 2003; 9(10): 23-26.

8. Cuaz-P'erolin C, Billiet L, Baug'e E, Copin C, ScottAlgara D, Genze F, Büchele B, Syrovets T, Simmet $\mathrm{T}$, Rouis $\mathrm{M}$, Antiinflammatory and antiatherogenic effects of the NF- $\kappa \mathrm{B}$ inhibitor acetyl-11- Keto- $\beta$ boswellic acid in LPS-challenged ApoE-/- mice. Arterioscler Thromb Vasc Biol., 2008; 28 (2): 272-277.

9. David W, Maimes S. Adaptogens, Herbs for Strength, Stamina, and Stress Relief, $1^{\text {st }}$ ed. Rochester Healing Arts Press, Vermont, 2007: 211-222.

10. Goyal C, Ahuja M, Sharma SK, Preparation and evaluation of anti-inflammatory activity of gugulipidloaded proniosomal gel. Acta Pol Pharm., 2011; 68(1): 147-150.

11. Haroyan A, Mukuchyan V, Mkrtchyan N, Minasyan N, Gasparyan S, Sargsyan A, Narimanyan M, Efficacy and safety of curcumin and its combination with boswellic acid in osteoarthritis: a comparative, randomized, double-blind, placebo-controlled study. BMC Complement Altern Med., 2018; 18: 7-19.

12. Hejazi II, Khanam R, Mehdi SH, Bhat AR, Moshahid ARM, Islam A, Thakur SC, Athar F, New insights into the antioxidant and apoptotic potential of Glycyrrhiza glabra L. during hydrogen peroxide mediated oxidative stress: An in vitro and in silico evaluation. Biomed Pharmacother., 2017; (94): 265-279.

13. Hinman RS, Hunt MA, Creaby MW, Wrigley TV, McManus FJ, Bennell KL, Hip muscle weakness in individuals with medial knee osteoarthritis. Arthritis Care Res., 2010; 62(8): 1190-1193.

14. Jia T, Qiao J, Guan D, Chen T, Anti-inflammatory effects of licochalcone a on IL-1 $\beta$-stimulated human osteoarthritis chondrocytes. Inflammation, 2017; 40(6): 1894-1902.

15. Kamal D, Traistaru R, Alexandru DO, Kamal KC, Pirici D, Pop OT, Malaescu DG, Morphometric findings in avascular necrosis of the femoral head. Rom J Morphol Embryol., 2012; 53(Suppl3): 763-767.

16. Kessler CS, Pinders L, Michalsen A, Cramer H, Ayurvedic interventions for osteoarthritis: a systematic review and meta-analysis. Rheumatol Int., 2015; 35(2): 211-232.

17. Kohn MD, Sassoon AA, Fernando ND, Classifications in brief Kellgren-Lawrence classification of osteoarthritis. Clin Orthop Relat Res., 2016; 474: 1886-1893.

18. Loukov D, Karampatos S, Maly MR, Bowdish DM, Monocyte activation is elevated in women with knee osteoarthritis and associated with inflammation, BMI and pain. Osteoarthritis Cartilage, 2017; (17): 10631084.

19. Malemud CJ, Anticytokine therapy for osteoarthritis: Evidence to date. Drugs \& Aging, 2010; 27: 95-115. 
20. Meselhy MR, Inhibition of LPS-induced NO production by the oleogum resin of Commiphora wightii and its constituents. Phytochemistry, 2003; 62 (2): 213-218.

21. More $\mathrm{P}$, Pai $\mathrm{K}$, Involvement of tyrosine-specific protein kinase and protein kinase $\mathrm{C}$ in J774A.1 macrophage functions activated by Tinospora cordifolia. J Ayurveda Integr Med., 2017; 8: 88-92.

22. Nazari S, Rameshrad M, Hosseinzadeh H, Toxicological effects of Glycyrrhiza glabra (Licorice): A review. Phytother Res., 2017; 31(11): 1635-1650.

23. Nan R, Grigorie D, Cursaru A, Șucaliuc A, Drăguț R, Rusu E, Mușat M, Radulian G, Bisphosphonates a good choice for women with type 2 diabetes and postmenopausal osteoporosis?. Farmacia, 2016; 64(2): 257-261.

24. Park YJ, Cho YR, Oh JS, Ahn EK, Effects of Tribulus terrestris on monosodium iodoacetate induced osteoarthritis pain in rats. Mol Med Rep., 2017; 16: 53035311.

25. Posadzki P, Watson L, Ernst E, Herb-drug interactions: An overview of systematic reviews. $\mathrm{Br} \mathrm{J}$ Clin Pharmacol., 2013; 75: 603-618.

26. Rastogi S, Bansal R, Kulkarni KS, Efficacy of Rumalaya tablets in arthritis - A double blind placebo controlled trial. The Antiseptic, 2001; 5(98): 172-173.

27. Rastogi S, Sivaraman ST, Kulkarni KS, Evaluating the safety and efficacy of Rumalaya forte: A doubleblind clinical trial. Orthopaedics Today, 2003; 1(V): 63-65.

28. Silverwood V, Blagojevic-Bucknall M, Jinks C, Jordan JL, Protheroe J, Jordan KP, Current evidence on risk factors for knee osteoarthritis in older adults: a systematic review and meta-analysis. Osteoarthritis and Cartilage, 2015; 23: 507-515.

29. Singh U, Kishore K, Seth SD, Comparative clinical study of indigenous drug with ibuprofen in patients of osteoarthritis. IJPMR, 1997; 8(9): 1997-1998.

30. Taneja DK, Chara GU, Rumalaya in osteoarthritis. The Antiseptic, 1975; 10(72): 527-534.
31. Traistaru MR, Kamal D, Kamal KC, Rogoveanu OC, Popescu M, Bondari S, Alexandru DO, Ionovici N, Grecu DC, Imaging and histopathological aspects in aseptic osteonecrosis of the femoral head. Rom $J$ Morphol Embryol., 2015; 56(4): 1447-1453.

32. Traistaru R, Popescu R, Gruia C, Rogoveanu O, A complex assessment of patiens with knee osteoarthritis and Baker's cyst - observational study. Rom J Morphol Embryol., 2013; 3(54): 593-601.

33. Tsonga T, Michalopoulou M, Malliou P, Godolias G, Kapetanakis S, Gkasdaris G, Soucacos P, Analyzing the history of falls in patients with severe knee osteoarthritis. Clinics in Orthopedic Surgery, 2015; 7: 449-456.

34. Umar S, Umar K, Sarwar AH, Khan A, Ahmad N, Ahmad S, Katiyar CK, Husain SA, Khan HA, Boswellia serrata extract attenuates inflammatory mediators and oxidative stress in collagen induced arthritis. Phytomedicine, 2014; 21(6): 847-856.

35. Van den Berg WB, Osteoarthritis year 2010 in review: Pathomechanisms. Osteoarthritis and Cartilage, 2011; 19: 338-341.

36. Vishal AA, Mishra A, Raychaudhuri SP, A double blind, randomized, placebo controlled clinical study evaluates the early efficacy of aflapin in subjects with osteoarthritis of knee. Int J Med Sci., 2011; 8: 615-622.

37. Zhang XP, Wei N, Huang J, Tan YF, Jin DJ, A new feruloyl amide derivative from the fruits of Tribulus terrestris. Nat Prod Res., 2012; 26(20): 1922-1925.

38. Zhu N, Rafi MM, DiPaola R S, Bioactive constituents from gum guggul (Commiphora wightii). Phytochemistry, 2001; 56(7): 723-727.

39. Zhu W, Du Y, Meng H, Dong Y, Li L, A review of traditional pharmacological uses, phytochemistry, and pharmacological activities of Tribulus terrestris. Chem Cent J., 2017; 11: 60-72. 